\title{
Intervenções para Reduzir o Estigma da Aids no Brasil: Uma Revisão Crítica
}

\author{
Eliana Miura Zucchi \\ Programa de Pós-Graduação em Saúde Pública da Universidade de São Paulo, \\ São Paulo, Brasil \\ Núcleo de Estudos para Prevenção da Aids da Universidade de São Paulo, São Paulo, Brasil \\ Vera Silvia Facciolla Paiva ${ }^{1}$ \\ Departamento de Psicologia Social e do Trabalho da Universidade de São Paulo, \\ São Paulo, Brasil \\ Núcleo de Estudos para Prevenção da Aids da Universidade de São Paulo, São Paulo, Brasil \\ Ivan França Junior \\ Departamento de Saúde Materno-Infantil da Universidade de São Paulo, São Paulo, Brasil \\ Núcleo de Estudos para Prevenção da Aids da Universidade de São Paulo, São Paulo, Brasil
}

\section{Resumo}

Este artigo analisou nove estudos sobre intervenções psicoeducativas para mitigar processos de estigma e discriminação relacionados ao HIV/Aids no Brasil. As intervenções ocorreram a partir de 1996, estando a maioria em andamento em 2002, seis anos após a disponibilização da terapia antirretroviral. Somente uma intervenção teve como objetivo instituir uma política anti-discriminatória com base no HIV no ambiente de trabalho, sendo as outras referentes a projetos de prevenção ao HIV com populações de caminhoneiros, moradores de favela, homens que fazem sexo com homens, de assistência a pessoas com HIV no trabalho e pesquisas sobre gênero e saúde sexual e reprodutiva de pessoas vivendo com HIV. As intervenções se diversificaram quanto à combinação dos tipos de estratégias empregadas, tais como ênfase na informação sobre infecção por HIV, desenvolvimento de habilidades para prática de sexo seguro e aconselhamento para situações de efetiva ou potencial discriminação. Nas ações de prevenção ao HIV, o enfrentamento dos estigmas associados à promiscuidade e pobreza foi interpretado como uma ação que repercutiu no aumento da prática de sexo seguro. No contexto das pesquisas, o manejo do estigma foi possível pelo compartilhamento de experiências reais ou potenciais de discriminação no trabalho ou na vida afetivo-sexual. Análises de intervenções de mitigação do estigma da Aids no Brasil são escassas e estão localizadas em nível comunitário de projetos de prevenção ao HIV ou em contextos de pesquisas conduzidas nos serviços especializados em DST/Aids. A análise de experiências anti-estigma de serviços de saúde ou de ONG tem recebido pouca reflexão acadêmica.

Palavras-chave: Intervenção, psicossocial, estigma, discriminação, Aids.

\section{A Critical Review on Aids Stigma Reduction Interventions in Brazil}

\section{Abstract}

We analyzed nine studies on psychosocial interventions to reduce HIV/AIDS-related stigma and discrimination in Brazil. Interventions began in 1996, being the majority in progress in 2002, six years

Endereço para correspondência: Departamento de Psicologia Social e do Trabalho, Instituto de Psicologia, Universidade de São Paulo, Av. Prof. Mello Moraes, 1721, Bloco A, Cidade Universitária, São Paulo, SP, Brasil 05508-900.E-mail: eliana.zucchi@uol.com.br, veroca@usp.bre ifjunior@usp.br 
after antiretroviral therapy was made available in Brazil. Only one intervention was specifically aimed at establishing a work policy of anti-discrimination based on HIV. Other publications referred to HIV prevention programs with truck drivers and community living in a shantytown, men who have sex with men, healthcare for people living with HIV at workplace, as well as research on sexual and reproductive health of people living with HIV. Interventions differed according to strategies, such as focus on provision of information on HIV infection, development of safer sex skills, and counseling in circumstances of actual or potential discrimination based on serostatus. As for HIV prevention projects, dealing with stigma related to 'promiscuity' and poverty was interpreted as promoting increase on safer sex practices. In the research context, the management of stigma was based on sharing lived or potential experiences of discrimination at work or in affective-sexual life. Analyses of AIDS stigma reduction interventions in Brazil are scarce and frequently part of HIV prevention programs at community-level or research carried out at STD clinics. The analysis of stigma reduction experiences in health services and NGOs has received little academic reflection.

Keywords: Intervention, socio-psychology, stigma, discrimination, AIDS.

\section{Las Intervenciones para Reducir el Estigma del SIDA en Brasil: Una Revisión Crítica}

\section{Resumen}

En este artículo se revisó nueve estudios de intervenciones psicoeducativas para mitigar el estigma y la discriminación relacionados con el VIH/SIDA en Brasil. Las intervenciones se produjo desde 1996, con la mayor parte ocurre en 2002, seis años después de la administración de la terapia antirretroviral. Sólo una intervención dirigida a establecer una lucha contra la discriminación basada en el VIH en el lugar de trabajo y otros proyectos relacionados con la prevención del VIH con poblaciones de camioneros, pobladores, hombres que tienen sexo con hombres, la asistencia a las personas con el VIH y el trabajo de investigación sobre género y salud sexual y reproductiva de las personas que viven con el VIH. Las intervenciones se han diversificado como la combinación de los tipos de estrategias de empleo, tales como el énfasis en la información sobre la infección por el VIH, el desarrollo de habilidades para la consejería sobre sexo seguro y las situaciones de discriminación real o potencial. En las acciones de prevención del VIH, se enfrentan al estigma asociado con la promiscuidad y la pobreza se interpretó como una acción que afectó al incremento de la práctica de sexo seguro. En el contexto de la investigación, la gestión del estigma fue posible mediante el intercambio de experiencias reales o potenciales de discriminación en el trabajo o la vida afectivo-sexual. Analiza las intervenciones para mitigar el estigma del SIDA en Brasil son escasas y se encuentran en los proyectos a nivel comunitario para prevenir el VIH o en contextos de investigación llevada a cabo en establecimientos especializados de ETS/SIDA. El análisis de las experiencias de lucha contra el estigma de los servicios de salud o de las ONG ha recibido poca reflexión académica.

Palabras clave: Intervención, psicosocial, estigma, discriminación, SIDA.

O reconhecimento do poderoso impacto negativo do estigma associado à Aids nos campos da prevenção e assistência, bem como nos direitos humanos, mobiliza a maioria dos estados e organizações internacionais para uma agenda de combate ao estigma como uma forma de controlar a epidemia. Tal compromisso se expressa na proposição de estratégias para identificação de estigma ou mensuração de discriminação, assim como na formulação de diretrizes de desenho, avaliação e monitoramento de intervenções voltadas a populações mais vulneráveis (Joint United Nations Programme on HIV/AIDS [UNAIDS], 2000, 2008). Adicio- 
nalmente, agências internacionais tem analisado os aspectos legais relacionados ao HIV/Aids que podem informar políticas de Estado (Gable, Gamharter, Gostin, Hodge, \& Puymbroeck, 2007), bem como disseminação de boas práticas em diversos níveis de resposta ao estigma e à discriminação (UNAIDS, 2005).

No Brasil, a história da resposta social à Aids tem se caracterizado pela ação de diferentes setores - Estado, instituições e sociedade civil - que, articulados ou não, fazem referência aos processos de estigmatização e discriminação relacionados ao HIV/Aids desde o início da epidemia (Paiva \& Zucchi, 2012). No final dos anos 1970, o movimento homossexual crescia e configurava uma identidade política coletiva de resistência para enfrentar, talvez como maior desafio, o início da expansão da Aids nos anos 1980 entre os homossexuais. A resposta à epidemia, por sua vez, encontrou nas redes de solidariedade e de combate à intensa homofobia da época, a inspiração para expandi-las como resposta também à Aids (Parker, 2003; Trevisan, 2000). No plano jurídico, tais respostas podem ser logo identificadas, por exemplo, com a instituição de leis que têm protegido pessoas que vivem com HIV de sofrerem discriminação e seus direitos com base em seu estado sorológico ${ }^{2}$, tanto no acesso à saúde integral quanto na permanência em ambientes educacionais, de trabalho, saúde, lazer, entre outros, resultado da forte pressão política do movimento de pessoas afetadas pela Aids (Berkman, Garcia, Muñoz-Laboy, Paiva, \& Parker, 2005; Galvão, 2005; Raupp Rios, 2003; Ventura, 2003). No âmbito institucional, ainda que em expressão mais tímida, a estratégia de planejamento familiar em serviços especializados em DST/Aids constituiu uma forma de garantir os direitos sexuais e reprodutivos das pessoas que vivem com HIV (Santos et al., 2002).

Se encontramos na literatura uma reflexão crítica sobre respostas sociais e estruturais à estigmatização e discriminação no campo da Aids, que balanço crítico poderíamos fazer hoje das

Lei $\mathrm{N}^{\mathrm{o}}$ 11.199, de 12 Julho 2002. (2002). Proíbe a discriminação aos portadores do vírus HIV ou às pessoas com AIDS e dá outras providências. Diário Oficial do Estado de São Paulo. ações psicoeducativas no campo da mitigação do estigma e da discriminação no Brasil? Que concepções e técnicas são utilizadas neste campo?

Para pensar o estigma, Erving Goffman (1922-1982) é autor obrigatório na formação de psicólogos e no campo das ciências sociais e trata do caso do estigma como expressão típica do interacionismo simbólico em sua teoria social, que historicamente fundamenta tanto a microssociologia como a psicologia social brasileira. Sua formulação original nos anos 1950 concebe o estigma como resultante da atribuição de uma identidade social deteriorada e da caracterização desviante da norma daqueles que possuem uma marca individual socialmente desvalorizada. Segundo Goffman, o estigma implica uma informação social que transmite:

signos . . especialmente efetivos para despertar a atenção sobre uma degradante discrepância de identidade que quebra o que poderia, de outra forma, ser um retrato global coerente, com uma redução consequente em nossa valorização do indivíduo (Goffman, 1980, p. 53).

Aprofundando e ampliando a concepção original de estigma para pensar a resposta à Aids no mundo na tradição dos estudos construcionistas e culturais, em especial no campo da sexualidade, Parker e Aggleton (2003) conceberam a estigmatização como um processo social- produtor de discursos, habitus e estruturas ${ }^{3}$ que o sustentam - e os processos de discriminação como aqueles que materializam, portanto, relações de poder e dominação, particularmente as de gênero, sexualidade, classe e raça, como se observa nas metáforas associadas à Aids. Tais relações dependem da produção social e cultural de significados atribuídos à "diferença" como "desvio" associados a "estereótipos" e, nesse sentido, a estigmatização é um processo social que reitera a desigualdade que tem uma história social. Em síntese, discutem os autores, no processo de estigmatização associados à Aids somam-se atributos desvalorizáveis e desacreditáveis que já desqualificavam segmentos de pessoas como portadores de direi-

3 Os autores integram em sua formulação Bourdieu, Foucault, entre outros. 
tos antes da infecção - como ser trabalhador do sexo, negro, usuário de drogas, homossexual ou desempregado. Os estigmatizados são, desde o início da epidemia, os "culpados", enquanto mulheres casadas, crianças e infectados em hospitais são "vítimas".

Uma importante contribuição teórico-metodológica das pesquisas em Aids tem sido justamente estabelecer conexões entre a compreensão do conceito sociológico interacionista de estigma e o campo da pesquisa social que pensa a produção das desigualdades, tendo como horizonte de igualdade a referência dos direitos humanos (Paiva, 2012; Paiva \& Zucchi, 2012; B. S. Santos, 2003). Dessa forma, a produção social da desigualdade geralmente leva a ações ou omissões que são danosas ou negligenciam o acesso de segmentos da população a determinados serviços, bens e posições sociais, caracterizando o estigma efetivado e, no campo do direito, a ausência de tratamento igual e justiça, a discriminação, definida como: "na ausência de justificativa objetiva, o sujeito sofre uma distinção que resulta em tratamento injusto direcionado a um grupo específico" (Maluwa, Aggleton, \& Parker, 2002). Do ponto de vista dos direitos, toda discriminação relacionada ao HIV/Aids possui a manifestação simbólica do estigma em um ato concreto (palavras, gestos, omissões, entre outros). Por outro lado, embora o estigma seja fruto de um processo social de construção simbólica em torno de uma identidade deteriorada, é insuficiente afirmar que toda experiência de estigma resultará em tratamento injusto sem incluí-la em contextos históricos de resistência. Goffman descreveu, no plano da interação interpessoal, que pessoas manipulam o estigma ou ocultam determinadas condições justamente para evitar situações de discriminação, o que poderíamos dizer em outros termos, produzindo resistência.

$\mathrm{O}$ estigma associado ao HIV/Aids e a consequente discriminação são formas específicas de violação dos direitos das pessoas que vivem com o HIV/Aids e de suas famílias. Adicionalmente, ambos podem vincular-se à violação de outros direitos humanos. Tanto o estigma quanto a discriminação e outras violações de direitos humanos associados ao HIV/Aids podem ter suas origens em políticas governamentais, em instituições privadas, comunidades e nas famílias das pessoas afetadas (Parker \& Aggleton, 2003). Os direitos humanos mais frequentemente violados são o direito ao emprego/ trabalho, ao casamento, à liberdade de ir e vir, à informação, à privacidade, à herança e o direito ao não-tratamento cruel e degradante (Maluwa et al., 2002).

Políticas públicas de abrangência nacional podem, além de promover a prevenção e assistência às DST/Aids, servir como importante ferramenta de combate os processos sociais de estigma e discriminação em populações afetadas. A concepção que tais ações podem expressar a perspectiva acumulada no debate das agências internacionais e, ao mesmo tempo, ser um "termômetro" da inclusão da agenda do movimento social nacional de pessoas afetadas pela Aids.

No curso da terceira década de epidemia no Brasil (em 2007, por exemplo, o Departamento de DST, Aids e Hepatites Virais do Ministério da Saúde lançou dois planos voltados a populações específicas que respondiam a uma análise da epidemia e à pressão do movimento social: o "Plano Integrado de Enfrentamento da Feminização da Epidemia de Aids e outras DST" e o "Plano Nacional de Enfrentamento da Epidemia de Aids e das DST entre Gays, HSH [homens que fazem sexo com homens] e Travestis"). Ambos mencionaram o estigma associado à discriminação e, como objetivo, reduzir vulnerabilidades por meio de políticas específicas de prevenção, promoção e atenção integral junto a esses segmentos. Os planos reivindicavam, também, a prioridade de ações nas esferas do executivo, legislativo e judiciário.

No caso das mulheres, para mitigação do estigma e da discriminação, o plano propunha ações específicas de investimento em capacitação permanente dos recursos humanos em saúde e educação com relação aos temas gênero, direitos humanos, direitos sexuais e direitos reprodutivos e violência, assim como o estabelecimento de políticas intersetoriais e integradas. O plano citava as conferências internacionais relativas aos direitos sexuais e reprodutivos e procurava contemplar a diversidade entre as mulheres, conforme ilustrado a seguir: 
Tomando como referência os Direitos Sexuais e os Direitos Reprodutivos (tais como proposto nas Conferências de Cairo 1994, Beijing 1995 e na I Conferência Nacional de Políticas para as Mulheres), as estratégias do Plano devem contemplar as mulheres e suas especificidades: gestantes; mulheres vivendo com HIV e aids; adolescentes e jovens; lésbicas, bissexuais e outras mulheres que fazem sexo com mulheres; transexuais, negras; indígenas; mulheres em situação de prisão; profissionais do sexo; trabalhadoras do campo e da cidade; mulheres em situação de violência sexual e doméstica; portadoras de deficiência; mulheres no climatério e as mulheres idosas. (Ministério da Saúde, 2007a, p. 20)

A segunda política indicava agendas específicas para gays/HSH e travestis (Ministério da Saúde, 2007b). Fundamentava uma agenda diferente para travestis pela insuficiência de dados epidemiológicos específicos nesse segmento, e por reconhecer condições de acrescida vulnerabilidade, tais como a violência, o contexto das práticas sexuais e de pior acesso aos serviços de saúde que resultavam na precariedade de adoção de práticas sexuais seguras. Parte considerável das suas diretrizes, assim como suas ações específicas, estava atravessada pelo discurso do respeito aos direitos humanos e pelo enfrentamento dos processos de estigma e discriminação marcados pela homofobia e transfobia. Por exemplo, a redução das vulnerabilidades às DST/Aids associadas às expressões da homofobia e transfobia institucional, social e individual é definida como objetivo. Dessa forma, grande parte das ações específicas no plano psicoeducativo refere-se à sensibilização e capacitação de profissionais e gestores para atender esses objetivos junto as populações de gays, HSH e travestis. Entre os objetivos está também a intervenção estrutural e social que se define pelo apoio a estados, municípios e sociedade civil bem como a articulação entre eles e com os meios de comunicação nessa mesma direção.

A noção de estigma e a discriminação relacionados à Aids tem mantido, portanto, destaque no debate público e nas ações políticas específicas que deveriam assegurar o direito à não-discriminação das pessoas que vivem com Aids. Não observamos, entretanto, a mesma consistência e constância do tema no âmbito da literatura acadêmica, em que se observa escassez de estudos. Como têm indicado revisões sobre estigma, discriminação e Aids no Brasil, na literatura predominam concepções de estigma como atributo ou experiência individual, sem considerar as formulações de estigma como processos sociais que materializam relações de poder e dominação como as que se produziram no campo da Aids (França \& Zucchi, 2013; Monteiro, Villela, \& Knauth, 2012). São raras também descrições densas e detalhadas das estratégias propostas para mitigação do estigma da Aids, como se observou nos planos do Ministério mencionados.

$\mathrm{Na}$ literatura internacional, as poucas intervenções para redução do estigma da Aids que foram avaliadas, por outro lado, têm apresentado resultados variados: há estratégias descritas como muito bem sucedidas por aumentarem a tolerância em relação às pessoas vivendo com HIV, bem como intervenções com efeitos apenas de curto prazo nas percepções e atitudes das pessoas (Brown, Macintyre, \& Trujillo, 2003).

Este texto pretende contribuir nessa direção e analisará criticamente a literatura sobre ações para mitigar processos de estigma e discriminação relacionados ao HIV/Aids no Brasil, focalizando as intervenções psicoeducativas (ou psicossociais) na literatura internacional frequentemente nomeadas como sócio-psicológicas $^{4}$, e no Brasil. Sem pretender esgotar toda a produção a respeito, ou abranger outras políticas ou ações estruturais (legais ou na mídia, por exemplo) de combate ao estigma ${ }^{5}$, focali-

4 Ou Socio-psychological. A tradição brasileira de psicologia social na saúde é distinta e prefere o termo psicossocial (Paiva, 2012). Alguns autores da tradição sócio-cognitiva da psicologia da saúde usam psicoeducativo, reconhecendo o teor de sua intervenção.

5 Sobre esse tema há muitos outros textos que discutem como a mobilização social pelo acesso à medicação e a opção por apoiar trabalhos de pre- 
zará artigos disponíveis online produzidos por pesquisadores ou disseminados por algumas das organizações não-governamentais (ONG) mais antigas e institucionalizadas que participam da resposta à epidemia no Brasil e que mantém um site atua- lizado.

\section{Métodos}

Procedemos a uma revisão bibliográfica utilizando cinco fontes de consulta disponíveis em meio eletrônico:

1. Biblioteca Virtual em Saúde (BVS Brasil) ${ }^{6}$ sem critério de periodização, Seção Literatura Científica e Técnica, a qual abrange bases de ciências da saúde em geral, tais como LILACS, IBECS, MEDLINE, Biblioteca Cochrane, SciELO, bem como de Organismos Internacionais, como a Organização Pan-Americana de Saúde (OPAS);

2. Site da $\mathrm{PubMed}^{7}$, o qual abrange literatura biomédica e de ciências da saúde disponível na bases de dados MEDLINE;

3. Biblioteca virtual da UNAIDS no Brasil ${ }^{8} \mathrm{e}$ sua Biblioteca virtual da UNAIDS internacional, seção 'Eliminating stigma and discrimination',

4. Site do Departamento de DST, Aids e Hepatites Virais do Ministério da Saúde (MS) do Brasil, seção Publicações. ${ }^{10}$

Tendo em vista a forte atuação da sociedade civil na resposta à epidemia de Aids no Brasil e no intuito de obter registros de estratégias volta-

venção baseados nas noções de diversidade sexual que têm sido também intervenções de combate ao estigma (Berkman et al., 2005; Castro \& Farmer, 2005).

6 Acesso à base de dados obtido pela Biblioteca Virtual em Saúde (BVS Brasil). Recuperado em http:// http://regional.bvsalud.org/php/index.php

7 US National Library of Medicine / National Institutes of Health. Retrieved from http://www.ncbi. nlm.nih.gov/pubmed

\& Programa Conjunto das Nações Unidas sobre HIV/Aids. Recuperado em http://www.unaids. org.br

9 UNAIDS.Retrieved fromhttp://www.unaids.org/en

10 Departamento de DST, Aids e Hepatites Virais do Ministério da Saúde do Brasil. Recuperado em http://www.aids.gov.br das à mitigação do estigma que não estivessem disponíveis em fontes convencionalmente acadêmicas ou institucionais ${ }^{11}$, incluímos na busca

5. Sites de organizações da sociedade civil, tais como (a) Site do Fórum de ONGs Aids do Estado de São Paulo, seção 'Arquivos e Publicações' e websites de organizações não-governamentais de diversos estados com expressiva atuação nos campos da sexualidade, educação e prevenção às DST/ Aids, a saber: (b) Associação Brasileira Interdisciplinar de Aids - ABIA (RJ) - seções 'Projetos' e Centro de Documentação e Recursos - CEDOC, (c) Cidadania, Orgulho, Respeito, Solidariedade, Amor - CORSA $(\mathrm{SP})^{12}$, (d) ECOS Comunicação em Sexualidade $(\mathrm{SP})^{13}$, (e) Grupo de Apoio à Prevenção à Aids - GAPA BR (SP) $)^{14}$, (f) Grupo Gay da Bahia (BA) ${ }^{15}$, (g) Grupo Pela VIDDA (SP) ${ }^{16}$, (h) Grupo de Incentivo à Vida - GIV (SP) ${ }^{17}$, (i) Grupo de Apoio à Prevenção da AIDS do Rio Grande do Sul - GAPA $(\mathrm{RS})^{18}$, (j) Grupo de Resistência Asa Branca - GRAB (CE) ${ }^{19}$, (k) SOMOS iguais, diversos e plurais $(\mathrm{RS})^{20},(1)$ Instituto Papai (PE) ${ }^{21}$ e (m) GESTOS Soro-positividade, Comuni-

11 Fórum de ONGs Aids do Estado de São Paulo. Re-cuperado em http://www.forumaidssp.org.br/site/

12 CORSA - Cidadania, Orgulho, Respeito, Soli-dariedade, Amor. Recuperado em http://corsa. wikidot.com/

13 ECOS Comunicação em Sexualidade. Recuperado em http://www.ecos.org.br/cedoc_projetos.asp

14 Grupo de Apoio à Prevenção à Aids - GAPA BR/ SP. Recuperado em http://www.gapabrsp.org.br

15 Grupo Gay da Bahia. Recuperado em http://www. ggb.org.br/ggb.html

16 Grupo Pela VIDDA. Recuperado em http://www. pelavidda.org.br/site/

17 GIV Grupo de Incentivo à Vida. Recuperado em http://www.giv.org.br/

18 Grupo de Apoio à Prevenção da AIDS do Rio Gran-de do Sul. Recuperado em www.gapars.com.br

19 Grupo de Resistência Asa Branca - GRAB (Ceará). Recuperado em http://www.grab.org.br/

20 SOMOS iguais, diversos e plurais. Recuperado em http://www.somos.org.br/

21 Instituto Papai. Recuperado em http://www.papai. org.br 
cação \& Gênero (PE). ${ }^{22}$ Foram selecionados para análise apenas os textos que apresentassem descrição de uma intervenção psicoeducativa/psicossocial que incluísse alguma ação para diminuir o estigma associado à Aids, mesmo que esta não fosse a principal finalidade da intervenção.

No que se refere ao planejamento da busca de literatura, estigma e preconceito são termos frequentemente empregados, em ambientes acadêmicos ou não, muitas vezes sem definição precisa. Ainda que os conceitos de estigma e preconceito guardem semelhanças quando descrevem processos de exploração/dominação e afirmação da norma social, estigma tem sido majoritariamente utilizado em pesquisas sobre doenças, deficiências ou desvios de comportamento ou de identidade (Phelan, Link, \& Dovidio, 2008), trata das interações e da intersubjetividade. Dessa forma, optamos por 'estigma' como termo de busca, adotando, posteriormente, combinações com 'aids' ou 'HIV' e palavras que expressassem intervenções de combate ao estigma, conforme descrito a seguir.

Ao consultar a literatura científica na BVS, a busca utilizou a seguinte estratégia: (estigma OR stigma) AND (AIDS OR HIV). Inicialmente identificamos 124 registros, dos quais 90 eram artigos. Dentre os artigos, 64 possuíam texto completo. Foram excluídas 21 publicações por não serem estudos conduzidos no Brasil. Excluímos 11 artigos de revisão ou comentários. Dos 32 artigos de pesquisa, quatro referiram ter realizado algum tipo de ação voltada à mitigação do estigma da Aids.

A estratégia de busca bibliográfica no site PubMed incluiu a combinação dos seguintes termos: 'AIDS', 'stigma', 'reduction' e 'intervention'. Essa busca retornou 39 ocorrências, das quais nenhuma apresentava intervenções de redução de estigma conduzidas no Brasil.

Na biblioteca virtual da UNAIDS no Brasil havia 52 documentos disponíveis no site em abril

22 GESTOS Soropositividade, Comunicação \& Gênero. Recuperado em http://www.gestos.org/principal/ de 2012. Embora diversos documentos reiterassem tanto o compromisso das agências internacionais, estados e sociedade civil no combate ao estigma da Aids, como a afirmação de conquistas nesse plano, nenhuma publicação apresentou efetivamente descrição de intervenções. A seção 'Eliminating stigma and discrimination' da página virtual da UNAIDS internacional continha quatro documentos em língua inglesa, dos quais dois apresentavam descrição de intervenções de combate ao estigma/discriminação, sendo, portanto, analisados.

A seção 'Publicações' do site do Departamento de DST, Aids e Hepatites Virais do MS não dispõe de um mecanismo de busca por palavra-chave, sendo o único filtro de consulta disponível a seleção por ordem alfabética dos títulos das publicações. Os critérios para acessar a versão completa das 432 publicações foram: (a) identificação de títulos que apresentassem as palavras 'estigma' ou 'discriminação' ou (b) publicações que enfatizassem grupos historicamente mais vulneráveis a sofrer processos de estigmatização e discriminação e, consequentemente, mais vulneráveis à infecção pelo HIV e adoecimento por Aids, tais como homens que fazem sexo com homens, profissionais do sexo, população negra e usuários de drogas. Nesta fonte, o único estudo encontrado no escopo de ação de promoção de saúde sexual em comunidade empobrecida (Edmundo, Souza, Carvalho, \& Paiva, 2007) já havia sido captado pela busca na base de dados BVS.

Os sites das ONG CORSA, GAPA(SP), GAPA(RS), GRAB, SOMOS, Instituto Papai e Gestos não apresentaram relatos de projetos ou descrições detalhadas de intervenções para mitigação de estigma. Encontram-se menções a projetos e relatórios nos sites das outras organizações onde, entretanto, nenhum detalhamento das estratégias e métodos utilizados é disponibilizado: o projeto De Cara Pra Vida, na ECOS, consiste na realização de oficinas para o fortalecimento da auto-estima e do exercício dos direitos sexuais e reprodutivos das mulheres vivendo com HIV/Aids; o Grupo Gay da Bahia realizou o Projeto Somos e o Grupo Pela VIDDA apresen- 
ta três projetos voltados à mitigação do estigma (Projeto Educar Para Viver, Projeto Viva-Voz Contra Estigmas e Programa Iec - Informação, Educação e Comunicação) e, sem maiores detalhes, apenas menciona realização de palestras, oficinas, distribuição de material de divulgação, entre outros, nos setores de educação, de inclusão social de pessoas vivendo com HIV e ambientes coorporativos. $\mathrm{Na}$ análise foi incluído o projeto da organização GIV de oficinas de apoio a mulheres com HIV e outro voltado à prevenção ao HIV entre homens que fazem sexo com homens (Projeto Homossexualidades \& Prevenção) da ABIA.

Foram identificados, assim, nove estudos que descreveram intervenções de mitigação de processos de estigmatização ou discriminação relacionados ao HIV/Aids no Brasil.

Para fins de análise, os artigos/documentos foram caracterizados de acordo com segmento visado pela estratégia e tipo de abordagem empregada nas práticas psicoeducativas/ psicossociais. Descrevemos as abordagens das estratégias conforme caracterização proposta por Brown et al. (2003), que sintetizaram intervenções de redução de estigma segundo quatro finalidades centrais:

1. Informação: intervenções centradas na transmissão de informação sobre diversos aspectos relativos à prevenção às DST/ HIV por meio de material impresso (folhetos, cartazes, entre outros) ou comunicações verbais (tais como aulas e palestras). A ênfase é dada principalmente em informações sobre modos de transmissão, prevenção e tratamento da doença;

2. Habilidades: intervenções que tem por finalidade o aprendizado de habilidades para resolver situações de conflitos em níveis individual ou em grupo. Exemplos incluem técnicas de sensibilização e ressignificação de estereótipos a partir da exposição de pequenos grupos a situações hipotéticas de alguma característica relacionada ao estigma da Aids como, por exemplo, a noção de 'grupo de risco'.
3. Aconselhamento: uma estratégia utilizada para veicular informação sobre HIV/Aids em situações com maior proteção para discussões privadas, assim como proporciona suporte social para mudança ou manutenção de comportamentos que trazem maior segurança. Grupos de apoio a pessoas vivendo com HIV/Aids são um exemplo dessa abordagem uma vez que é oferecido um ambiente seguro para que se possa discutir dificuldades relacionadas à revelação diagnóstica. $\mathrm{O}$ aconselhamento também pode incluir técnicas para desenvolvimento de habilidades;

4. Contato: uma estratégia que inclui o contato com grupos afetados, prevê a criação de situações de interação direta ou indireta entre pessoas vivendo com HIV/Aids e público em geral. Parte-se do pressuposto de que, por exemplo, testemunhos de pessoas com HIV promovem uma relação mais próxima como o público, o que, por sua vez, contribui para desmitificar estereótipos relacionados ao estigma da Aids, dando lugar à empatia com quem vive com Aids.

\section{Análise dos Resultados}

As nove intervenções identificadas ocorreram entre 1996 e 2011 e cinco delas estavam em atividade no ano de 2002, seis anos após a introdução do acesso universal e gratuito à terapia antirretroviral de alta potência no Brasil, que tem sido um marco na diminuição do estigma associado à Aids (Berkman et al., 2005; Castro \& Farmer, 2005). A Tabela 1 apresenta síntese das principais características dos estudos, segundo a classificação de finalidades proposta por Brown et al., 2003 (informação, habilidades, aconselhamento, contato) o grupo participante e as atividades realizadas. 
Tabela 1

Síntese das Intervenções Analisadas Segundo Estratégias, Objetivos, Participantes e Atividades Desenvolvidas. Brasil, 1996 a 2011

Autor \&

Período da Intervenção

Objetivos e Grupo

Participante

Atividades Realizadas

Finalidades

(1)

VW Brasil

(1996 -2002)

Informação

Aconselhamento

(2)

GIV e Rede Paulista de

Mulheres com HIV/Aids (1997)

Informação

Habilidades

Aconselhamento

Contato

(3)

Chinaglia et al.

(2002-2005)

Informação

Habilidades

Aconselhamento

(4)

Edmundo et al.

(2001-2004)

Informação

Habilidades

Aconselhamento

(5)

Garrido, Paiva, Nascimen-

to, Sousa, \& Santos

Paiva, Segurado, \& Filipe

(2001-2002)

Informação

Habilidade

Aconselhamento

Contato
Melhorar tratamento de pessoas vivendo com HIV. Promover política anti discriminatória

Participantes: trabalhadores de empresa automobilística

Oferecer oficinas como estratégias de apoio as mulheres, com base em suas representações sobre gênero, sexualidade e autoestima.

Participantes: mulheres vivendo com HIV.

Aumentar oferta de serviços de HIV e de saúde em geral, com base na problematização do estereótipo "caminhoneiros = vetores de doenças". Participantes: caminhoneiros de rota longa.

Promover saúde sexual e prevenção ao HIV e combater a 'sinergia de pragas' associadas ao HIV/ Aids e observadas na vida de moradores de favelas.

Participantes: moradores de comunidade de favela.

Lidar com as dificuldades no ambiente de trabalho, nos relacionamento afetivos e sexuais.

Participantes: homens com HIV que fazem sexo com mulheres. (a) Serviços para assistência de funcionários com HIV e garantia de confidencialidade de estado sorológico.

(b) Informação por meio de mídia e distribuição de preservativo.

(c) Proibição do teste anti-HIV para admissão, demissão.

(a) Nove oficinas sobre os temas Aids, relações de gênero, autoestima, sexualidade, cidadania e participação das mulheres em grupos em encontros mensais. As estratégias foram a discussão, brincadeiras, dramatizações, pintura, argila, massagem, dinâmicas, exposição de vídeo, entre outros.

(b) Avaliação ao final de cada encontro por todos os participantes.

(a) Agentes de prevenção para sensibilização e aconselhamento individual e em grupo.

(b) Capacitação de profissionais.

(c) Oferta de serviços de HIV e de saúde em geral.

(d) Distribuição de material educativo e de preservativos por profissionais.

(a) Envolvimento de líderes comunitários para todo o processo.

(b) Agentes de prevenção realizaram aconselhamento em grupo, com discussão de práticas de sexo mais seguro.

(c) Distribuição de preservativos por agentes comunitários.

(d) Capacitação de agentes comunitários.

No contexto de pesquisa sobre saúde sexual e reprodutiva de homens vivendo com HIV organizaram-se, depois de discutir resultados, cinco grupos de discussão específicos para cada tema indicado pelos participantes, nas quais se discutiram dúvidas e problemas levantados pelos homens. Realizados em serviço especializado em DST/Aids. 
(6)

Silva \& Ayres

(2007-2008)

Informação

Habilidade

Aconselhamento

Contato

(7)

ABIA (2008 -2011)

Informação

Habilidades

Aconselhamento

Contato
Discutir comunicação

diagnóstica a parceiros

sexuais atuais, passados e futuros.

Participantes: mulheres vivendo com HIV.

Diminuir vulnerabilidade individual e social ao HIV/Aids \& Desenvolver parcerias institucionais locais, nacionais e maior intercâmbio internacional para a prevenção do HIV e da Aids.

Participantes: homens que fazem sexo com homens soronegativos e soropositivos.
No contexto de pesquisa sobre comunicação diagnóstica de HIV a parceiros sexuais.

Atividade baseada em trabalho com este grupo no serviço especializado em DST/Aids.

Duas sessões de grupo educativo para ampliação de repertório argumentativo.

Dramatização de situações para acessar sentidos, afetos e valores.

(a) No contexto de pesquisa multicêntrica e mapeamento de locais de homossociabilidade.

(b) Intervenções para distribuir informação e insumos (lubrificantes e preservativos) em boates, bares, praia, vídeolocadoras e sex shop.

(c) Produção de materiais informativos.

(d) Oficinas e formação de agentes multiplicadores de informação e monitores sobre homossexualidade, preconceitos e a epidemia de HIV/AIDS.

(e) Organização de exposições artísticas sobre trabalho produzido pelos participantes.

(f) Produção de documentário para profissionais da saúde para diminuir o estigma e preconceito em relação a pessoas vivendo com HIV de orientação homossexual.
Como se nota na Tabela 1, as intervenções analisadas são bastante abrangentes e quase sempre incluem todos os elementos elencados por Brown et al. (2003), embora só incluam o contato com pessoas vivendo com Aids quando o grupo abordado é de soropositivos. Ao mesmo tempo, nota-se que mesmo quando se pensa desenvolvimento de habilidades, as ações excedem bastante o grupo que seria beneficiário direto $\mathrm{e}$ participante da intervenção e inclui profissionais que estariam em contato com o grupo - assumindo, portanto, que para lidar com o estigma e a discriminação ao menos a dimensão programática - nesses trabalhos focalizando o setor saúde - que aumenta a vulnerabilidade à discriminação com base no estigma. As estratégias de aconselhamento individual ou em sessões psicoeducativas/psicossociais em grupo que buscavam também o fortalecimento das pessoas como sujeitos de direito (ABIA, 2011; Garrido, Paiva, Nascimento, Sousa, \& Santos, 2007; GIV, 2003; Paiva, Segurado, \& Filipe, 2011; Silva \& Ayres, 2009). A intervenção junto aos HSH, ainda, estabeleceu parcerias institucionais, com setores da sociedade civil e da esfera pública. Nenhuma ini- ciativa relatou a interação entre pessoas vivendo com HIV e público em geral, modalidade técnica bastante presente na literatura internacional.

As concepções de estigma que informam essas ações são fundamentais para entender esse quadro. De modo geral, as publicações apresentaram na formulação mesma do objeto de investigação, Garrido et al. (2007), assim como Silva e Ayres (2009), definem estigma segundo formulação original de Goffman e as subsequentes formulações dos processos de estigmatização das pessoas vivendo com Aids (Parker \& Aggleton, 2003), como produtos culturais e de poder, bem como apresentam o compromisso assumido pelos organismos internacionais para mitigar o impacto do estigma e discriminação relacionados ao HIV/Aids. Sem uma definição conceitual clara, os outros textos discutem consequências do processo de estigmatização na vida cotidiana de pessoas afetadas pela Aids, tais como a dificuldade de revelação do estado sorológico para parceiros sexuais (Paiva et al., 2011) e aceitação de um destino fatalista sem perspectiva de mudança em uma comunidade de favela ("um dia você vai ficar burro mesmo, tão te dando 
aquela marca") em níveis individual e coletivo, conforme apontado por Edmundo et al. (2007). Nesse mesmo sentido, ABIA (2011) e Chinaglia et al. (2007) também indicam o processo de estigmatização associado à Aids como um dos principais obstáculos à adoção de medidas de prevenção, bem como acesso e utilização de serviços de saúde nas populações de caminhoneiros e HSH.

A intervenção dedicada a promover o acesso a saúde de trabalhadores de indústria automobilística (UNAIDS, The Prince of Wales Business Leaders Forum, \& The Global Business Council on HIV \& AIDS, 2000) destaca-se das outras porque deixou de apresentar um delineamento da intervenção construído ou modificado com base na participação do segmento populacional envolvido, o que não permite inclui-lo, no quadro dos direitos humanos (Gruskin \& Tarantola, 2008, 2012; Paiva, 2012).

Os objetivos das intervenções, descritas em maior ou menor detalhe, variaram quanto a sua dedicação a compreensão da dinâmica social e psicossocial de produção da desigualdade. As representações e relações de gênero marcaram a oferta de apoio a mulheres e homens vivendo com HIV (Garrido et al., 2007; GIV, 2003), à prevenção ao HIV (ABIA, 2011; Chinaglia et al., 2007; Edmundo et al., 2007), à assistência a pessoas vivendo com HIV (UNAIDS et al., 2000), a dificuldade de acesso ao trabalho (Garrido et al., 2007) e a saúde sexual e reprodutiva de pessoas vivendo com HIV (Paiva et al., 2011; Silva \& Ayres, 2009).

Apresentamos a seguir uma síntese mais detalhada das intervenções, cronologicamente, e caracterizando seus antecedentes, suas atividades e resultados obtidos.

\section{Qualidade de Vida do Trabalhador com HIV na Volkswagen do Brasil}

O programa foi instituído em 1996, em São Bernardo do Campo (SP), em um contexto de crescente ocorrência de HIV entre os trabalhadores, alto custo com sucessivas hospitalizações e altas taxas de absenteísmo. Seus objetivos foram proporcionar um serviço eficiente aos trabalhadores para prevenir o aumento de custos relacionados à Aids, promover política anti-discriminatória de proteção aos trabalhadores com HIV e conduzir paralelamente um programa de prevenção ao HIV.

As ações adotadas incluíram palestras, aconselhamento (sem especificação de como foi feito) e utilização de mídia no ambiente de trabalho (rádio, intranet, jornal e folhetos) para divulgação de informações aos trabalhadores em geral. Foram instaladas máquinas de preservativos. Os trabalhadores também participaram de atividades organizadas pelo 'National Business Board for the Prevention of HIV/AIDS', do qual a empresa era membro. Além das medidas adotadas para melhorar assistência às pessoas com HIV, as medidas de não discriminação da empresa previam proibição da obrigatoriedade de teste de HIV e de demissão de funcionários com HIV, bem como o direito à confidencialidade destes funcionários.

Como resultados, ao final do programa em 2000 , a empresa relata que era perceptível a diminuição nas hospitalizações, no custo com tratamento de HIV e no absenteísmo e relata melhora da qualidade de vida das pessoas com HIV no ambiente de trabalho, bem como aumento na percepção de satisfação no trabalho de modo geral.

\section{O Projeto GIV \& Rede Paulista de Mulheres com HIVIAids}

Com base nas representações das mulheres sobre gênero, sexualidade e autoestima, o projeto realizou oficinas como estratégias de apoio para melhorar sua qualidade de vida (GIV). Em seguida, as mulheres infectadas pelo HIV participaram de oficinas sobre os temas Aids, relações de gênero, autoestima, sexualidade, cidadania e participação das mulheres em grupos com encontros mensais. Como metodologia, foram utilizadas discussões, brincadeiras, dramatizações, pintura, argila, atividades corporais, dinâmicas, exposição de vídeo, entre outros. Avaliação era feita ao final de cada encontro.

Como resultado anotado, as mulheres participantes relataram o aprendizado de "coisas" novas e muito interesse nos temas discutidos eram motivos alegados para continuar participando das oficinas: ressaltavam a importância 
da convivência entre pares, de poder rir juntas, identificando-se com a problemática e vivência das outras mulheres e das discussões em grupo; sentiram-se acolhidas e com espaço para obter informações, relatam forças "renovadas", aumento da autoestima e da valorização como mulher. Os responsáveis pelo projeto conduzido pela Rede de Mulheres Vivendo com HIV destacam que as dificuldades enfrentadas foram desistências ou faltas motivadas por doença, dificuldade de acesso, falta de agendamento, distância entre uma oficina e outra; dificuldade de lidar com a temática, problemas de ordem diversa (filhos e família) e outros compromissos, dificuldade de participar de grupos e manter relacionamento coletivo.

\section{O Projeto entre Caminhoneiros de Rota Longa na Região de Fronteira do Estado do Paraná}

Também considerando dados preliminares de uma pesquisa que, em 2002, indicava que os caminhoneiros eram altamente sensíveis ao estereótipo negativo que associava caminhoneiros como vetores de doenças (Chinaglia et al., 2007). Dessa forma, o desenho da intervenção ampliou o escopo da atenção à saúde sexual e testagem para HIV para outros serviços de saúde que fossem do interesse dos caminhoneiros. Assim, instalados em pontos de alfândega novos serviços incluíam testagem voluntária, aconselhamento, tratamento para DST passaram a incluir prevenção de outras doenças. As mensagens na mídia para disseminá-los valorizavam a categoria profissional, enquanto agentes de prevenção realizavam distribuição de material educativo e sessões de orientação individual e em grupo, testagem e aconselhamento para DST e HIV, tratamento para essas e outras doenças, além de oficinas fora da unidade para nutrição e hipertensão.

Como resultado relatado indica-se que depois de 32 meses (em 2005), a intervenção aumentou a testagem para HIV e o uso de preservativo em parcerias casuais e obteve boa avaliação pelo grande número de participantes, com relatos de que foi uma iniciativa 'não estigmatizante'.

\section{Promoção da Saúde Sexual em Favela na Região Metropolitana do Rio de Janeiro}

Os moradores haviam indicado o HIV/Aids como "prioridade para ação de políticas públicas, e a prevenção foi entendida como um ponto de entrada para o desafio contra a sinergia de pragas" que enfrentavam (Edmundo et al., p. 129) - um contexto de violência e exploração sexual decorrente da pobreza e do narcotráfico. A comunidade também vivia um contexto de exposição pública da sexualidade resultante da falta de privacidade típica de suas moradias precárias.

Em 2001, foram realizadas entrevistas e grupos focais com diversos participantes: líderes comunitários, agentes de prevenção, moradores frequentadores e não frequentadores do núcleo comunitário que desenvolveu o projeto, lideranças religiosas, profissionais e jovens. Os temas abordados incluíram DST/HIV/Aids, sexualidade, contracepção e reprodução, família, lazer, trabalho, qualidade de vida, planos de futuro e resposta da comunidade às ações do núcleo. Com base nos resultados desse estudo preliminar foi organizado um espaço físico do núcleo para reunião dos moradores e a ação direta de um agente comunitário de prevenção, com domínio dos códigos locais, o que garantiu a discussão de práticas de sexo mais seguro. A distribuição de preservativos foi feita regularmente e mediante inscrição dos moradores, embora a quantidade não fosse suficiente para atendimento da demanda local. Quanto à participação, jovens de modo geral foram bastante assíduos e participativos nas atividades conduzidas.

Entre os resultados da intervenção (desenvolvida até 2004), moradores relataram iniciar uso de preservativo a partir da exposição de cartazes e conversas realizadas no núcleo e de conversas sobre práticas sexuais como uma forma de discutir informações sobre sexo seguro. A intervenção mostra a factibilidade de ações de promoção de sexo mais seguro nesses contextos onde também se combateu o estigma da pobreza associada à Aids na medida que problematizou concepções que naturalizam a ideia de uma comunidade 'destinada' à falta de proteção e exposição. 


\section{Promoção da Saúde Sexual e no Trabalho de Pessoas Vivendo com HIV}

Três publicações que abordam intervenções sobre o estigma são provenientes de pesquisas sobre saúde sexual e reprodutiva de mulheres vivendo com HIV (Silva \& Ayres, 2009) e com homens parceiros soropositivos dessas mulheres (Garrido et al., 2007; Paiva et al., 2011), outras em que se buscava facilitar a adesão ao preservativo e à medicação anti-HIV, todas realizadas em serviços especializados em DST/HIV/Aids no município de São Paulo. As intervenções definiram que o compartilhamento de experiências em grupo e a discussão sobre as formas de enfrentamento dos processos de estigma e discriminação em decorrência da Aids seria imprescindível.

$\mathrm{O}$ estudo realizado com as mulheres foi desenhado com a participação de profissionais de saúde e pacientes a partir da observação da dificuldade de mulheres em falar sobre sua infecção aos parceiros sexuais. As sessões de grupo educativo com mulheres tinham por finalidade ampliar o repertório argumentativo das participantes em relação à comunicação do diagnóstico aos parceiros sexuais presentes, passados ou futuros (Silva \& Ayres, 2009). Algumas mulheres não se viam na possibilidade de um relacionamento ou encontro mais íntimo em função do medo de revelar seu estado sorológico aos parceiros e recorreu-se à estratégia de dramatização de situações para acessar sentidos, afetos e valores envolvidos no momento da comunicação.

Todos os estudos realizados com pessoas vivendo com HIV concordam que não há uma única receita para lidar com o estigma e que grupos de apoio constituem um círculo social alternativo que lida com o isolamento.

É emblemática a cena dramatizada em Silva e Ayres (2009) sobre a decisão de uma das mulheres em revelar o estado sorológico ao parceiro de uma relação que estava se estreitando há alguns meses. Dentre os desfechos observados, dois expressaram rompimento ou aceitação do parceiro imediatamente após a comunicação diagnóstica, sem nenhum tipo de controvérsia. Por outro lado, foi dramatizada uma situação em que houve transformação do papel do sujeito - da condição de estigmatizado ao sujeito de direitos -, conforme ilustrado no relato a seguir:

$\mathrm{M}$ (mulher): Eu quero contar uma coisa. Eu sou soropositiva! P (homem): Você não poderia ter feito isso comigo! [reação violenta] M: Mas não houve nada entre nós, portanto, não houve risco! P: [nervoso] Eu vou processá-la! M: [com dificuldade, trêmula] Eu é que vou processá-lo! Por discriminação!

Os autores denominam de "gestão do estigma" a organização das ações de comunicação aos parceiros sexuais orientada pelo estigma associado à Aids (Silva \& Ayres, 2009). Se, por um lado, alguns profissionais ignoram o estigma ou recorrem a mecanismos de tutela do paciente, a experiência com o grupo de mulheres inclui elementos relacionados à conjugabilidade e proporcionou a passagem do papel de vítima para o de sujeito em condições de argumentar e defender seus direitos.

Nos estudos realizados com os homens hetero/bissexuais, entrevistas individuais resultaram em intervenções psicoeducativas em grupos de discussão sobre quatro temas escolhidos de comum acordo com os homens: desejo e possibilidade de ter filhos, dificuldade em conseguir trabalho e manter-se empregado, preconceito, dificuldade nos relacionamentos afetivos e sexuais ou em iniciar um novo relacionamento. Os grupos tinham como finalidade apoiá-los como "sujeitos dos cuidados à saúde" especificamente em situações de trabalho e relacionamento afetivo. Foi observado que o compartilhamento de experiências com outros homens na mesma condição problematizou estereótipos (por exemplo, de "inválidos" para o trabalho) e normas rígidas sobre revelação da sorologia a(o) parceira(o), bem como disseminou entre os participantes modos de resistir aos processos de estigmatização ou discriminação. Conduzidos no serviço de saúde, diversos homens relataram desconforto em participar de grupos de apoio existentes, frequentados majoritariamente por ativistas do movimento LGBT, definidos como "espaços homossexuais" com os quais não tinham identificação ou não queriam se vincular. 


\section{O Projeto Homossexualidades e Prevenção}

Seguindo estudos preliminares, foi conduzido pela ABIA no Rio de Janeiro ${ }^{23}$, entre 2008 a 2011 (ABIA, 2012). Seu objetivo era diminuir a vulnerabilidade individual e social ao HIV/Aids, manter parcerias institucionais locais, nacionais e maior intercâmbio internacional na prevenção HIV/Aids e continuar pesquisas voltadas à população de HSH soronegativos e soropositivos. A partir do mapeamento dos locais de homossociabilidade, foram realizadas intervenções psicoeducativas em boates, bares, praia, vídeo-locadoras e sex shop. Materiais informativos foram produzidos e utilizados em oficinas e formação de agentes multiplicadores de informação e monitores sobre homossexualidade, preconceitos e a epidemia de HIV/Aids, inclusive na distribuição de insumos de prevenção (preservativos e gel lubrificante). Ampliando para uma abordagem mais estrutural em benefício de $\mathrm{HSH}$, foram realizadas também exposições artísticas sobre trabalho produzido pelos participantes e produção de documentário destinado a profissionais da saúde para diminuir o estigma e preconceito em relação às pessoas vivendo com HIV/Aids com orientação homossexual. Adicionalmente, houve reforço da parceria com programas em escolas e unidades de saúde, favorecendo a inclusão de temas relacionados à saúde sexual de jovens homossexuais, homofobia em serviços básicos de saúde e educação, bem como participação em comitês de acompanhamento de projetos, organização de eventos e elaboração de documentos oficiais sobre saúde de HSH.

Os resultados principais da intervenção foram a ampliação do nível de informação entre jovens gays sobre saúde sexual, integração entre jovens gays e em redes de sociabilidade, além da sensibilização com profissionais de saúde para melhorar o acolhimento de usuários homossexuais nos serviços de saúde. Entre as dificuldades encontradas, a mobilização do público $\mathrm{HSH}$ para visitas às unidades de saúde pública e arti-

23 Em rede com outras organizações não governamentais, GRAB e SOMOS, que não incluem em suas páginas os resultados desses projetos. culação com Secretaria de Educação do Estado do Rio de Janeiro foram as mais expressivas.

Em síntese, nenhum desses estudos tinha como objetivo específico tratar da mitigação do estigma e da discriminação. Com avaliação de processo e tipicamente qualitativos, trataram de processos de estigmatização associados ao HIV voltados para a prevenção (uso de preservativo, estereótipos, acesso à atenção à saúde integral) ou ao adoecimento por Aids no caso dos projetos com pessoas vivendo com Aids (estigmatização que viola direitos sexuais e reprodutivos, o direito ao trabalho e produz isolamento e sofrimento mental).

Os resultados das intervenções em termos de redução de estigma variaram em função dos objetivos de cada ação. A intervenção realizada com os trabalhadores da VW não apresentou indicadores precisos da redução do estigma, ainda que desfechos como melhora da qualidade de vida e de satisfação no trabalho tenham sido relatados. Por outro lado, os estudos de prevenção ao HIV com caminhoneiros e moradores de favela apresentaram como indicadores de resultado o aumento do uso de preservativo no contexto da participação dos grupos nas discussões das práticas de sexo seguro que levavam em consideração os estereótipos relacionados à promiscuidade ("caminhoneiros são vetores de doença”) e pobreza.

Já os resultados das oficinas com mulheres com HIV, dos grupos focais de homens vivendo com HIV no contexto da pesquisa de saúde sexual e reprodutiva, tipicamente qualitativos, discutiram a possibilidade de manejo do estigma por meio do compartilhamento de experiências, tais como problematizar como as representações de gênero interferem na possibilidade de prazer sexual com HIV, o rótulo de "homem com Aids é inválido para o trabalho", normas rígidas de revelação para o parceiro e formas de reação aos processos de estigmatização. Os dois grupos psicoeducativos com mulheres vivendo com HIV trabalhou alternativas a potenciais situações de discriminação na impossibilidade de revelação da condição de HIV positiva ao parceiro sexual, lidando com a condição de vítima e ampliando o repertório para agir como sujeito de direitos. 
Os estudos da ABIA (2011), Edmundo et al. (2007) e GIV (2003) indicaram limitações ou dificuldades na intervenção, expressas pelo absenteísmo nas oficinas (por motivo de doença e principalmente com mulheres), falta de acesso a insumos para prevenção e impossibilidade de atingir determinados grupos, tais como mulheres que sofrem violência, membros de igreja e homens que recusam o uso do preservativo no trabalho com comunidade e dificuldades de inclusão da população HSH nos serviços de saúde e no estabelecimento de parceria com a Secretaria da Educação. Os demais estudos não referiram quaisquer obstáculos às atividades conduzidas.

\section{Discussão}

A maior parte das intervenções analisadas estava em curso em um contexto em que já estava consolidada a disponibilização de tratamento antirretroviral como direito no Brasil, instituída em 1996 (Galvão, 2005). Não foram encontrados textos sobre intervenções psicossociais ou psicoeducativos para redução de estigma na primeira década da epidemia, período mais contundente de discriminação associada à Aids no Brasil - apesar dos relatos na mídia de inúmeras atividades de mobilização social em solidariedade às pessoas vivendo com HIV, registradas por diversos autores (Berkman et al., 2005; Galvão, 1997; Parker, 2003) e que reagiam a diversos casos de violação de direitos humanos como a recusa de hospitais e profissionais de saúde em abrigar ou tratar adequadamente pessoas doentes com Aids em vários estados do País (Mott, 1996) e de inúmeras atividades de mobilização social em solidariedade às pessoas vivendo com $\mathrm{HIV}$, registradas por diversos autores (Berkman et al., 2005; Galvão, 1997; Parker, 2003). Assim, a reflexão sobre intervenções surgem tardiamente na resposta brasileira.

A maior parte das intervenções na literatura internacional dedicam-se especificamente ao aumento da tolerância na convivência com as pessoas vivendo com HIV/Aids - seja na população geral, seja entre estudantes universitários e profissionais de saúde (Brown et al., 2003; Mahajan et al., 2008). O que torna o conjunto dos estudos brasileiros analisados diferente do observado na literatura internacional é a ausência de publicações brasileiras sobre intervenções psicoeducativas em que a mitigação do estigma da Aids seria o objetivo principal, além da metodologia das intervenções e as chamadas "população-alvo", como veremos a seguir.

Destaca-se das demais a estratégia implementada pela VW do Brasil (Tabela 1). Embora tenha sido indicada como 'best practice' de combate ao estigma da Aids pelo Programa de Aids das Nações Unidas (UNAIDS et al., 2000) e ressaltasse uma política anti-discriminatória como objetivo, o indicador de sucesso da intervenção foi a melhora da capacidade produtiva do trabalhador, expressa por indicadores de diminuição de custo e número de hospitalizações e absenteísmo. Anterior à literatura que validou as abordagens no quadro dos direitos humanos em saúde, o texto não problematiza os processos sociais de desigualdade como parte dos estigmas associados à Aids (pobreza, sexismo, homofobia e orientação sexual), conforme observado nas intervenções relatadas pelos outros textos analisados. Não valoriza, também, a qualidade da participação dos trabalhadores (elegendo temas de interesse, por exemplo). Não obstante, a literatura mais recente (Ferreira, Figueiredo, \& Souza, 2011) indica que pessoas que revelam ter HIV no ambiente de trabalho ainda enfrentam situações de discriminação ou de potencial discriminação, particularmente em situações que colegas temem se infectar ou quando se trata de uma mulher gestante com HIV. Esse tipo de intervenção continua sendo necessária duas décadas depois.

Com relação às metodologias utilizadas, as demais intervenções psicoeducativas ou psicossociais podem ser incluídas no campo das abordagens em saúde no quadro dos direitos humanos e combinam diferentes abordagens e informação sobre diversos temas junto à população, tornando-se relevantes para o processo de intervenção sobre o modo como as experiências de estigmatização se manifestam na vida cotidiana. $O$ formato "oficina" e grupos de "discussão", como se sabe, sempre associa a disseminação de informação ao aconselhamento provido por participan- 
tes e técnicos envolvidos. Outra característica de tais intervenções refere-se à participação dos grupos abordados no delineamento da intervenção como um fator que, segundo as abordagens baseadas em direitos humanos (Gruskin \& Tarantola, 2008), aumenta a factibilidade e as chances de sucesso das ações, como foi observado no caso do aumento da realização de teste anti-HIV, do uso de preservativos e a avaliação positiva do efeito em sua vida por parte dos participantes em vários dos estudos citados. Ainda nessa direção, à ressignificação do indivíduo como sujeito de direito ao cuidado integral e à prevenção (Paiva \& Zucchi, 2012), tratada nas várias intervenções que mencionam a redução estigma como parte de seus objetivos, somam-se exemplos de efeitos da intervenção na assunção do direito de não ser discriminado, como no relato de uma mulher que reage à ameaça do parceiro: "Eu é que vou processá-lo! Por discriminação!" (Silva \& Ayres, 2009). Finalmente, a necessidade de desconstrução de processos de estigmatização associados a esses segmentos como parte de uma estratégia para promover saúde - "caminhoneiros são vetores de doenças porque são promíscuos" e "moradores de favela estão sujeitos à Aids porque são desamparados pela pobreza e violência locais" é expressa tanto no delineamento como no efeito subjetivo entre os que participaram no decorrer dos quatro anos destas intervenção.

Nas abordagens e metodologias brasileiras, o contato com pessoas afetadas é mais amplo que o contato com pessoas vivendo com HIV que se observa e propõe na literatura internacional. O manejo do estigma pelo contato, portanto, é possível pelo compartilhamento de experiências reais ou potenciais de discriminação por processos de estigmatização associados ao HIV em determinados territórios (na favela) ou profissões (caminhoneiros) e, no caso dos projetos com pessoas vivendo com HIV, trata-se de contato com experiências vividas por outros/outras na mesma condição no ambiente de trabalho ou na vida afetivo-sexual.

No âmbito do desenvolvimento de habilidades, estas também são concebidas de modo ampliado, menos individual. A dimensão do sofrimento individual decorrente da estigma- tização associada à Aids é abordada por meio da aquisição de novos repertórios não apenas dos participantes diretamente afetados (pessoas vivendo com HIV, trabalhadores, moradores de favelas), mas de profissionais cuja obrigação seria atendê-los em seu "direito à saúde integral", que as abordagens de direitos humanos indicam como necessários para lidar com esse tipo de situação de modo mais eficaz. De todo modo, combinam-se estratégias de aconselhamento e informação, como também observaram Brown et al. (2003). Enquanto houver estigma, esta é uma tarefa pertinente às intervenções que pensam o processo de estigmatização e a vulnerabilidade aos agravos de saúde decorrentes deles (sofrimento mental, evolução da doença, entre outros) implicadas no plano individual, mas também social e programático.

Um limite deste estudo e característica a ressaltar no esforço de busca por textos para incluir na análise é o modo de disponibilizar e, em especial, a demora ou mesmo falta de divulgação das avaliações de políticas públicas e programas depois do período previsto de conclusão. Até o momento, não há relatos disponíveis por meio eletrônico ao público em geral, publicados em revistas acadêmicas ou mesmo no site do Departamento de DST, Aids e Hepatites Virais do MS, ainda que este último tenha definido as ações e as metas de enfrentamento da feminização da epidemia da Aids e de outras DST, assim como o enfrentamento desta entre Gays, HSH e Travestis previstos até 2010 e 2011, respectivamente, como discutido na introdução. A disponibilização de relatórios, ainda que parciais, sobre o andamento desses planos, entre outros financiados informariam sobre o processo e eventuais avanços, bem como os obstáculos encontrados. Tais planos englobam os grupos reconhecidamente mais vulneráveis à infeção por HIV. ${ }^{24}$ Relatório independente produzido sobre a resposta brasileira à agenda específica para trabalhadoras do

24 A saber HSH e mulheres profissionais do sexo, com taxas de infecção por HIV, respectivamente, de $10,5 \%$ e 5,1\%, segundo Relatório de Progresso da resposta Brasileira ao HIV/Aids (2010-2011) em relação às metas da UNGASS (Ministério da Saúde, 2012). 
sexo referente ao Plano de Feminização (ABIA, 2011) indica que preconceito, estigma e discriminação permanecem como temas recorrentes nas entrevistas com gestores e profissionais de saúde em Porto Alegre e no Rio de Janeiro que, embora demonstrassem grande sensibilidade para as questões de estigma, preconceito e discriminação, mantinham muitos vieses no tratamento recebido por profissionais do sexo.

Outros trabalhos dedicados a temas do conviver com Aids nos anos 1980 e 1990, como já comentamos, são de difícil acesso e não aparecem nas buscas sistemáticas quando se aborda a mitigação de estigma, merecendo novas pesquisas em bases de dados nessa direção. Sabe-se que o investimento em oficinas e grupos de compartilhamento, um modo de disseminar informação/aconselhar/por em contato e treinar habilidades, foram, desde os anos 1980, uma abordagem utilizada em serviços e organizações não governamentais que, embora tivessem como foco outros temas (oficinas de adesão ao preservativo e a medicação como os primórdios do que se chamou depois de coquetel anti-HIV), necessariamente tratavam de processos de estigmatização, embora usando outros termos como "preconceito". O debate sobre a revelação do diagnóstico positivo para o HIV, por exemplo, sempre aborda temas associados à estigmatização, indicando estratégias de lidar com esse processo inventadas pelas pessoas afetadas:

$\mathrm{O}$ isolamento ou esconder o diagnóstico pode ser uma resposta saudável. Grupos ajudam a romper o isolamento, que a paciente às vezes não sabe como minimizar, e podem constituir uma família substituta (Tunala et al., 2000, p. 82).

Por outro lado, a desconstrução de metáforas da Aids associadas aos grupos mais vulneráveis à infecção que produz o processo de estigmatização depende de outras ações programáticas. Investimentos de ampla abrangência, tais como trabalho com prevenção em escolas e utilização da mídia por ONG Aids têm sido indicados como ações efetivas para redução dos níveis de estigma em países como a India (Kandwal \& Bahl, 2011).

Há diversas outras intervenções relatadas na literatura para diminuir a incidência de DST e aumentar o uso de preservativo, como o projeto com trabalhadoras do sexo em Corumbá, onde se conseguiu ressignificar a condição de mulher estigmatizada (Murray, Lippman, Donini, \& Kerrigan, 2010), nesse caso, pela prostituição, objeto da intervenção. Este projeto foi delineado a partir da combinação de diferentes estratégias clínicas, comportamentais e sociais e obteve entre as mulheres abordadas a percepção de benefícios psicológicos e de saúde, motivada para modificar positivamente seu status individual.

No caso dos textos que analisamos ou da literatura disseminada internacionalmente, a dificuldade está na definição e avaliação de estigma, bem como a incerteza quanto ao alcance e duração do impacto das intervenções. Há controvérsia quanto ao alcance das intervenções de redução de estigma em ambientes de saúde destinadas a pessoas com Aids junto a profissionais de saúde (Uys et al., 2009).

Por outro lado, é inegável que as inúmeras intervenções que buscam, desde o início da epidemia, no plano jurídico ou institucional assegurar o direito à não-discriminação de pessoas vivendo com HIV e reiterar a diversidade sexual como direito, contribuem para evitar a discriminação e a desconstrução dos atributos estereotipados que sustentam a violação de direitos (e a desigualdade) das pessoas afetadas pela Aids. Análises críticas feitas por organizações não-governamentais de projetos de lei de criminalização da transmissão do HIV (Guimarães, 2011), bem como ações no âmbito da educação escolar compõem, mesmo que indiretamente, ações institucionais e governamentais de combate ao estigma da Aids. Iniciativas de prevenção ao HIV nas escolas (ou a ausência delas) conduzidas pelas ONG e no setor público têm reforçado a problematização da homofobia, do racismo e da norma religiosa que se opõe à noção de direitos sexuais e reprodutivos têm contribuído para o sucesso (ou insucesso) de ações de combate ao estigma na comunidade escolar (ABIA, 2008; Zucchi, Barros, Paiva, \& França, 2010). Certamente, há uma dimensão psicossocial e psicoeducativa nos efeitos que produzem quando se aumenta a qualidade da informação sobre o efeito dos processos de estigmatização e a inaceitabilidade da discriminação, incentivando mudança 
de mentalidades e atitudes que contribuem tanto para a mitigação dos estigmas associados à Aids como para atribuição cultural de décadas da "Aids como problema dos outros", que impede a prevenção e o autocuidado em uma epidemia eventualmente controlada, mas longe de acabar (Piot, Kazatchkine, Dybul, \& Lob-Levyt, 2009).

\section{Palavras Finais}

Em função da variedade das bases de informação consultadas - acadêmicas, institucionais e da sociedade civil - esperávamos encontrar mais relatos de intervenções psicoeducativas ou psicossociais especificamente voltadas para mitigar os estigmas associados à Aids. Ao incluir sites institucionais e de diversas ONGs brasileiras como fonte de busca, procuramos enfatizar também a produção não acadêmica, mas com grande potencial de circulação e divulgação.

As revisões internacionais sobre intervenções psicoeducativas/psicossociais de combate ao estigma da Aids $^{25}$ permitiram a identificação de duas intervenções brasileiras e em língua inglesa, portanto, de acesso mais restrito a profissionais e ativistas que têm se debruçado sobre esse tema. Claramente, as intervenções psicoeducativas ou psicossociais para mitigar o estigma, por certo existentes nas ONG e serviços de saúde antes e depois do ARV, não têm sido alvo de reflexão crítica e acadêmica em nosso país, como já notaram Monteiro et al. (2012) acerca da produção acadêmica sobre estigma no Brasil.

Nas intervenções analisadas em que, com uma exceção, se concebeu estigma como processo social, foram poucos os relatos de intervenções que se debruçaram especificamente sobre a condição individual e social relacionada à Aids que produz a percepção de inferioridade ou de tratamento desigual. Análises sobre mitigação do estigma da Aids no Brasil são de intervenções psicoeducativas localizadas em nível comunitário, no bojo de projetos de prevenção ao HIV, ou em contextos de pesquisas conduzidas em instituições (ONG e serviços de

25 Em bases de dados como Pubmed, Sociofile, Psychinfo e no site da UNAIDS. saúde) especializados em DST/Aids que atendem pessoas vivendo com HIV. Pode-se atribuir esse resultado à influência de abordagens menos individualistas, marcadas pela singularidade da resposta à Aids no Brasil que tem forjado, ao fazer, um novo modo de pensar as abordagens psicossociais e psicoeducativas em saúde, no quadro dos direitos humanos, mais adequados ao contexto e princípios do Sistema Único de Saúde (Paiva, 2012).

Por outro lado, se não contemplam especificamente a mitigação de estigma da Aids ou sua decorrente discriminação como objetivo ou em seu planejamento, diversos projetos e intervenções de prevenção de DST/HIV e gravidez assim como as ações, majoritariamente mobilizadas pela sociedade civil e no campo da educação, voltadas ao reconhecimento e valorização da diversidade sexual e da afirmação da cidadania sexual, dão conta de uma das características mais relevantes do plano da produção simbólica e da reprodução da organização social implicadas no processo de estigmatização associada à Aids: o sexismo e a homofobia que sustenta a desigualdade nas relações de gênero e da cidadania LGBT.

Considerando a expressão do ativismo brasileiro na resposta à Aids, um dos limites desse estudo é o fato, bastante provável, de as diversas intervenções finalizadas ou em curso, não produzirem relatos de acompanhamento ou avaliação que as disseminam amplamente: relatórios e artigos não estão disponíveis online, modo de busca dominante nessa segunda década do século 21. No caso dos diferentes projetos financiados por verbas do orçamento de estado, nem mesmo um detalhamento do que de fato estão fazendo está disponível online - o que facilitaria a absorção mais ampla das lições aprendidas nesses projetos.

No processo de revisão crítica ficou claro que, mesmo no cenário internacional, estudos que descrevem densamente e analisaram intervenções psicoeducativos para diminuição do estigma associado à Aids ainda são escassos se comparados aos estudos que abordam seu impacto psicossocial. A maior parte das intervenções psicoeducativas relatadas são ainda con- 
duzidas na América do Norte e Europa onde, eventualmente, as condições culturais e políticas produzem ou sustentam menos desigualdade, ou a perspectiva dos direitos humanos em saúde é menos valorizada, ou, como no caso dos EUA, não existe o contexto de um sistema único de saúde que protege o direito à saúde. As intervenções podem, portanto, ser descoladas da preocupação com a proteção de direitos.

É possível que a ausência de medidas de resultado da redução do estigma, ou ainda, as diferentes formas de avaliá-la, reflitam também dificuldades na mensuração desses processos, que a literatura mais recente reconhece como complexos e dinâmicos (Mahajan et al., 2008). As medidas disponíveis ainda enfatizam a experiência individual e não o compreendem como processo social. Como no Brasil a resposta à Aids se deu no contexto da construção do Sistema Único de Saúde, a noção de processo social e de combate a discriminação de direitos parecem ser mais presentes no cenário brasileiro. As intervenções de mitigação do estigma incorporam mais explicitamente o quadro dos direitos humanos: os princípios do Sistema Único de Saúde (SUS) de universalidade do acesso, igualdade e equidade, integralidade e participação (controle social) são centrais às abordagens em saúde baseadas em direitos humanos.

Será bastante produtivo se, além de identificar violações de direitos das pessoas afetadas e produzir uma linguagem com importante efeito na subjetivação, no autocuidado das pessoas afetadas, na qualidade do conhecimento e das atitudes no âmbito da prevenção a que todos têm direito, se possa oferecer, como discutiram Gruskin e Tarantola $(2008,2012)$ um quadro de análise para avaliar ações no campo da saúde e informar processos de trabalho que reduzam o estigma que afeta a vida de pessoas e sustenta organizações sociais injustas.

\section{Referências}

Associação Brasileira Interdisciplinar de Aids. (2008). Chegou levantando a poeira!: Notas sobre as apresentações da Companhia da Saúde em escolas da Baixada Fluminense. Coleção ABIA: Vol. 2. Cidadania e direitos. Rio de Janeiro, RJ: Autor.
Associação Brasileira Interdisciplinar de AIDS. (2011). Sexualidade e desenvolvimento: A politica brasileira de resposta ao HIV/AIDS entre profissionais do sexo (Relatório de pesquisa). Rio de Janeiro, RJ: Autor.

Associação Brasileira Interdisciplinar de Aids. (2012). Relatório Global 2011. Rio de Janeiro, RJ: Autor.

Berkman, A., Garcia, J., Muñoz-Laboy, M., Paiva, V., \& Parker, R. (2005). Critical analysis of the Brazilian Response to HIV/AIDS: Lessons learned for controlling and mitigating the epidemic in developing countries. American Journal of Public Health, 95(7), 1162-1172.

Brown, L., Macintyre, K., \& Trujillo, L. (2003). Interventions to reduce HIV/AIDS stigma: What have we learned? AIDS Education and Prevention, 15(1), 49-69.

Castro, A., \& Farmer, P. (2005). Understanding and addressing AIDS related stigma: From anthropological theory to clinical practice in Haiti. American Journal of Public Health, 95(1), 53-59.

Chinaglia, M., Lippman, S. A., Pulerwitz, J., Mello, M., Homan, R., \& Díaz, J. (2007). Reaching truckers in Brazil with non-stigmatizing and effective HIV/STI services (Horizons Final Report). Washington, DC: Population Council. Retrieved August 13, 2010, from http://www. popcouncil.org/pdfs/horizons/BrazilTruckersReport.pdf

Edmundo, K., Souza, C. M., Carvalho, M. L., \& Paiva, V. (2007). Vulnerabilidade ao HIV em favela do Rio de Janeiro: Impacto de uma intervenção territorial. Revista de Saúde Pública, 41(Supl. 2), 127-134.

Ferreira, R. C. M., Figueiredo, M. A. C., \& Souza, L. B. (2011). Trabalho, HIV/AIDS: Enfrentamento e dificuldades relatadas por mulheres. Psicologia em Estudo, 16(2), 259-267.

França, I., Jr., \& Zucchi, E. M. (2013). Fragilidades teórico-metodológicas na produção acadêmica brasileira sobre estigma em aids. Manuscrito em preparação.

Gable, L., Gamharter, K., Gostin, L. O., Hodge, J. G., Jr., \& Puymbroeck, R. V. V. (2007). Legal aspects of HIV/AIDS: A guide for policy and Law reform. Washington, DC: The World Bank.

Galvão, J. (1997) As respostas das organizações não-governamentais brasileiras frente à epidemia de 
HIV/ AIDS. In R. Parker (Org.), Políticas, instituições e AIDS: Enfrentando a epidemia no Brasil (pp. 67-108). Rio de Janeiro, RJ: Associação Brasileira Interdisciplinar de Aids.

Galvão, J. (2005). Brazil and access to HIV/AIDS drugs: A question of human rights and public health. American Journal of Public Health, 95(7), 1110-1116.

Garrido, P. B., Paiva, V., Nascimento, V. L. V., Sousa, J. B., \& Santos, N. J. S. (2007). Aids, estigma e desemprego: Implicações para os serviços de saúde. Revista de Saúde Pública, 41(Supl. 2), 72-79.

Goffman, E. (1980). Estigma: Notas sobre a Manipulação da Identidade Deteriorada. Rio de Janeiro, RJ: Zahar.

Grupo de Incentivo à Vida. (2003). Fios da Vida. Tecendo o feminino em tempos de Aids. Recuperado em 15 de abril, 2003, de http://www.aids.gov. $\mathrm{br} /$ final/biblioteca/fios_vid/creditos.htm

Gruskin, S., \&Tarantola, D. (2008). Universal access to HIV prevention, treatment, and care: Assessing the inclusion of human rights in international and national strategic plans. AIDS, 22(Suppl. 2), 123-132.

Gruskin, S., \&Tarantola, D. (2012). Um panorama sobre Saúde \& Direitos Humanos In V. Paiva, J. R. Ayres, \& C. M. Buchalla (Orgs.), Vulnerabilidade e Direitos Humanos - Prevenção e Promoção à Saúde - Da Doença à Cidadania (pp. 23-33). Curitiba, PR: Juruá.

Guimarães, M. (2011). HIV/AIDS não é sentença de morte: Uma análise crítica sobre a tendência à criminalização da exposição sexual e transmissão sexual do HIV no Brasil. Coleção ABIA: Vol. 3. Cidadania e Direitos. Rio de Janeiro, RJ: Associação Brasileira Interdisciplinar de Aids.

Joint United Nations Programme on HIV/AIDS. (2000). Protocol for the identification of discrimination against people living with HIV. Geneva, Switzerland: Author.

Joint United Nations Programme on HIV/AIDS. (2005). HIV-related stigma, discrimination and human rights violations: Case studies of successful programmes. Geneva, Switzerland: Author.

Joint United Nations Programme on HIV/AIDS. (2008). A framework for monitoring and evaluating HIV prevention programmes for most-at- risk populations. Geneva, Switzerland: Author.

Joint United Nations Programme on HIV/AIDS. (2010, June 22-24). Non-discrimination in HIV responses. Paper presented at the 26th Meeting of the UNAIDS Programme Coordinating Board, Geneva, Switzerland.

Joint United Nations Programme on HIV/AIDS, The Prince of Wales Business Leaders Forum, \& The Global Business Council on HIV and AIDS. (2000). The Business Response to HIV/AIDS: Impact and lessons learned. Geneva, Switzerland: Joint United Nations Programme on HIV/ AIDS.

Kandwal, R., \& Bahl, T. (2011). Link to slower access to care: What is the stigma? An Indian perspective. Current HIV/AIDS Report, 8, 235-240.

Mahajan, A. P., Sayles, J. N., Patel, V. A., Remien, R. H., Sawires, S. R., Ortiz, D. J., Coates, T. J. (2008). Stigma in the HIV/AIDS epidemic: A review of the literature and recommendations for the way forward. AIDS, 22(Suppl. 2), S67S79.

Maluwa, M., Aggleton, P., \& Parker, R. (2002). HIV and AIDS-related stigma, discrimination and human rights: A critical overview. Health and Human Rights, 6(1), 1-15.

Ministério da Saúde. (2007a). Plano Integrado de Enfrentamento da Feminização da Epidemia de Aids e outras DST. Brasília, DF: Autor.

Ministério da Saúde. (2007b). Plano de Enfrentamento da Epidemia de Aids e das DST entre Gays, HSH e Travestis. Brasília, DF: Autor.

Ministério da Saúde. (2012). UNGASS Metas: Relatório de Progresso da Resposta Brasileira ao HIV/AIDS (2010-2011). Brasil. Brasília, DF: Autor.

Monteiro, S., Villela, W. V., \& Knauth, D. (2012). Discrimination, stigma, and AIDS: A review of academic literature produced in Brazil (20052010). Cadernos de Saúde Pública, 28(1), 170176.

Mott, L. (1996). Aidsfobia: A violação dos direitos humanos das pessoas com HIV/Aids no Brasil. Cadernos de Textos do Grupo Gay da Bahia, 2.

Murray, L. R., Lippman, S. A., Donini, A. A., \& Kerrigan, D. (2010). 'She's a professional like anyone else': Social identity among Brazilian sex workers. Culture, Health \& Sexuality, 12(3), 293-306. 
Paiva, V. (2012). Cenas da vida cotidiana: Metodologia para compreender e reduzir a vulnerabilidade na perspectiva dos direitos humanos. In V. Paiva, J. R. Ayres, \& C. M. Buchalla (Orgs.), Vulnerabilidade e Direitos Humanos - Prevenção e Promoção à Saúde - Da Doença à Cidadania (pp. 165-208). Curitiba, PR: Juruá.

Paiva, V., Segurado, A. C., \& Filipe, E. M. V. (2011). Self-disclosure of HIV diagnosis to sexual partners by heterosexual and bisexual men: A challenge for HIV/AIDS care and prevention. $\mathrm{Ca}$ dernos de Saúde Pública, 27(9), 1699-1710.

Paiva, V., \& Zucchi, E. (2012). Estigma, discriminação e saúde: Aprendizado de conceitos e práticas no contexto da epidemia de HIV/Aids. In V. Paiva, J. R. Ayres, \& C. M. Buchalla (Orgs.), Vulnerabilidade e Direitos Humanos - Prevenção e Promoção à Saúde - Da Doença à Cidadania (pp. 111-143). Curitiba, PR: Juruá.

Parker, R. (2003). Building the foundations for the response to HIV/AIDS in Brazil: The development of HIV/AIDS policy, 1982-1996. Divulgação em Saúde para Debate, 27, 143-183.

Parker, R., \& Aggleton, P. (2003). HIV and AIDSrelated stigma and discrimination: A conceptual framework and implications for action. Social Science and Medicine, 57, 13-24.

Phelan, J., Link, B., \& Dovidio, J. F. (2008). Stigma and prejudice: One animal or two? Social Science and Medicine, 67, 358-367.

Piot, P., Kazatchkine, M., Dybul, M., \& Lob-Levyt, J. (2009). AIDS: Lessons learnt and myths dispelled. Lancet, 374(9685), 260-263.

Raupp Rios, R. (2003). Legal responses to the HIV/ AIDS epidemic in Brazil. Divulgação em Saúde para Debate, 27, 228-238.

Santos, B. S. (2003). Por uma concepção multicultural de direitos humanos. In B. S. Santos (Org.), Reconhecer para libertar. Os caminhos do cosmopolitismo multicultural (pp. 427-463). Rio de Janeiro, RJ: Civilização Brasileira.
Santos, N. J. S., Buchalla, C. M., Fillipe, E. V., Bugamellia, L., Garcia, S., \& Paiva, V. (2002). Mulheres HIV positivas, reprodução e sexualidade. Revista de Saúde Pública, 36(4, Supl.), 12-23.

Silva, N. E. K., \& Ayres, J. R. C. M. (2009). Estratégias para comunicação de diagnóstico de HIV a parceiros sexuais e práticas de saúde. Cadernos de Saúde Pública, 25(8), 1797-1806.

Trevisan, J. S. (2000). Devassos no paraíso: A homossexualidade no Brasil, da colonia à atualidade. Rio de Janeiro, RJ: Record.

Tunala, L. G., Paiva, V., Filipe, E. M. V., Santos, T., Santos, N., \& Hearst, N. (2000). Fatores psicossociais que dificultam a adesão das mulheres portadoras do HIV aos cuidados de saúde In Tá dificil de engolir?(pp. 79-114). São Paulo, SP: Centro de Referência e Treinamento DST/AIDS.

Uys, L., Chirwa, M., Kohi, T., Greeff, M., Naidoo, J., Makoae, L., Holzemer, W. L. (2009). Evaluation of a health setting-based stigma intervention in five African Countries. AIDS Patient Care and STDs, 23(12), 1059-1066.

Ventura, M. (2003). Strategies to promote and guarantee the rights of people living with HIV/AIDS. Divulgação em Saúde para Debate, 27, 239-246.

Zucchi, E. M., Barros, C., Paiva, V., \& França, I., Jr. (2010). Estigma e discriminação vividos na escola por crianças e jovens órfãos por Aids. $E d u$ cação e Pesquisa, 36(3), 719-734.

Recebido: 11/09/2012

$1^{a}$ revisão: $11 / 09 / 2012$

$2^{a}$ revisão: $25 / 02 / 2013$

Aceite final: 12/03/2013 